Acta Poetica 26 (1-2)

PRIMAVERA-OTOÑO

2005

\title{
La representación literaria de la transmisión oral. El caso de la nouvelle medieval
}

\author{
María Cristina Azuela
}

Uno de los rasgos distintivos del género de la nouvelle es que se trata de textos breves que se presentan en conjunto como producto de un círculo de narradores donde cada relato es transmitido. Lo anterior pone de relieve el tema de la representación literaria de la actividad oral que resulta importante, no sólo tal como aparece en el marco narrativo, sino también al interior de las historias. La palabra pronunciada parece ser, por otra parte, uno de los elementos en que se basa la pretensión a la veracidad de lo que se ha contado: el narrador aduce que sólo repite lo que ha oído o le han platicado. Sin embargo, en las nouvelles, las palabras en realidad son empleadas para engañar y confundir a los otros, lo que nos lleva a un cuestionamiento no sólo de la palabra pronunciada, sino de la propia palabra literaria.

Nouvelles can be characterized as short stories belonging to a story-collection. In general, there is a narrative frame where several narrators tell these stories. Literary representation of oral activity is thus a main issue of this genre, not only in the narrative frame, but also within each story. Narrative authentication relies largely on speech, as narrators pretend to report only what they have heard. Nevertheless, in the nouvelles words are uttered mainly to deceive. This raises questions on the uncertainty not only of oral utterances but also of literary discourse itself. 
María Cristina Azuela

Instituo de Investigaciones Filológicas, UNAM

\section{La representación literaria de la transmisión oral. El caso rle la nouvelle medieval ${ }^{1}$}

El género de la nouvelle tal como aparece al final del medioevo, aunque sus orígenes puedan rastrearse en obras tan remotas como Las mil y una noches, combina la tradición oral, a la que pertenecen la mayor parte de las historias narradas en cada relato, con la particularidad innegable de que se trata ya de textos escritos para ser leídos.

En este trabajo voy a considerar tres de los ejemplos más importantes de obras de nouvelles medievales: el Decamerón (1352), los Cuentos de Canterbury (1382) $)^{2}$ y las Cent Nouvelles nouvelles (1462). Entre la gran variedad de géneros de

' Este trabajo se basa, con algunas modificaciones, en un artículo publicado en francés en la revista Romania como: "L'activité orale dans la nouvelle médiévale: Les Cent Nouvelles nouvelles, le Décaméron, et les Contes de Canterbury" (Romania 115, 1997, 519-535). Todas las citas de los textos originales han sido traducidas por mí, cotejándolas, para la obra italiana, con la traducción de María Hernández Esteban, y en el caso del texto francés, con la versión al francés moderno (Dubuis 1991) Para las Cent Nouvelles nouvelles cito la edición de Sweetser 1996; para el Decamerón, la edición de Branca 1985; y la de Riverside 1988 para los Cuentos de Canterbury y La Casa de la Fama [The House of Fame].

${ }^{2}$ Dada la enorme variedad de historias incluidas en los Cuentos de Canterbury, me voy a limitar a las más emparentadas con las nouvelles de las obras italiana y francesa, sobre todo los cuentos del molinero, del mayordomo, del alguacil y del comerciante, aunque mencione otros relatos, como el del bulero, para ejemplificar algún detalle. 
relato corto del medioevo como lais, fabliaux o dits, las nouvelles se caracterizan por presentarse como parte constitutiva de un conjunto mayor que las engloba, y no como unidades independientes. Las obras de nouvelles no son simples antologías de historias breves, pues en general ofrecen un marco narrativo que establece lazos orgánicos entre todos los relatos que contienen. ${ }^{3}$

\section{El círculo de narradores y la oralidad}

El marco narrativo pone en escena a un "círculo de narradores", quienes relatarán cada una de las nouvelles de la obra. En los Cuentos de Canterbury se describe detalladamente la reunión de los peregrinos que durante su trayecto hacia Canterbury narrarán los distintos cuentos que componen el texto. Igualmente en el Decamerón se introduce desde la primera jornada al "alegre grupo" de diez jóvenes que, por huir de la peste florentina, se refugian en una villa campestre, donde serán relatadas las historias de Boccaccio. En las Cent Nouvelles nouvelles el marco narrativo no es explícito; sin embargo, en su mayor parte los relatos vienen encabezados por el nombre de su narrador - quie es un personaje histórico de la corte de Borgoña- ${ }^{4}$ y al interior de éstos no dejan de aparecer constantes alusiones al grupo de narradores ("Mientras tengo un buen auditorio, quiero contar..."). ${ }^{5}$ Hay, además

3 Véase Zumthor 1972, 404 y también la discusión de Cooper acerca de la story-collection, definida como conjunto de historias separadas que un solo autor escribió, o más bien reescribió y compiló, que circula como un todo unificado y coherente. Cooper divide la estructura de estas obras en tres tipos: aquellas que cuentan con un marco narrativo; aquellas donde sólo aparece un prólogo y un epílogo; y aquellas donde los relatos no vienen unificados de ninguna forma (1983, capítulo I).

${ }^{4}$ Se trata, en su mayoría, de nombres históricamente documentados de cortesanos del duque de Borgoña, que Champion identificó en su edición de la obra (1928).

5 "Tantdiz que j'ay bonne audience, je veil compter..." (nouvelle 93, líneas 5 6; véase también la nouvelle 81, líneas 4-7). 
repetidas referencias a un "ustedes" que "escuchan" las narraciones, ${ }^{6}$ que incluso consideradas como simples fórmulas convencionales heredadas de la tradición oral (Rasmussen 1958, 18), tienen un papel estratégico para dar verosimilitud, como lo discutiremos más adelante. Es importante destacar que algunas de las alusiones a la reunión de narradores revelan también la existencia de un proyecto preestablecido de realizar colectivamente una antología de historias por lo que cada narrador producirá un número determinado de relatos ante los demás (véase la nouvelle 32, líneas 4-10).

Es pues, como lo afirma Pérouse,

en la presentación de los narradores, y de las circunstancias mismas de su reunión, en la historia de su conversación [si se le puede llamar así al intercambio de relatos] donde se encuentra el origen y la sustancia misma del género (Pérouse 1977, 24).

De esta manera, si el rasgo distintivo del género de la nouvelle es el círculo de narradores, lo que se pone de relieve es el asunto de la actividad oral.

Se ha afirmado que el arte de narrar es el tema principal del marco narrativo de los Cuentos de Canterbury y del Decamerón y aunque en las Cent Nouvelles nouvelles, dicho "círculo de narradores" se encuentra apenas esbozado, la actividad oral también es fundamental dentro de cada narración. En todos los casos, no se trata únicamente de la simple reproducción del proceso de transmisión de las historias dentro del marco narrativo, sino que al interior mismo de cada historia este proceso se reproduce en una suerte de caja china donde el hecho de narrar, y de narrarse unos a otros, adquiere una importancia extrema.

${ }^{6}$ Frases del tipo de: "como habéis oído" (nouvelle 42, línea 158) se repiten constantemente (al respecto véase el capítulo I de Azuela 2006). 
Los personajes de los relatos charlan, van a confesión, se revelan sus secretos, se espían para oír lo que los otros dicen y, amenazándose mutuamente con el descrédito público, propagan toda clase de rumores con singular disposición y rapidez. A veces parecería que el simple hecho de hablar constituye su actividad más importante y, en otras ocasiones, es suficiente contar algo a alguien para desencadenar toda la acción de la historia. ${ }^{7}$

A menudo un personaje no está satisfecho con tener conocimiento de los hechos, sino que necesita oírlos de boca de otro para creerlos. Vemos así que Katherine (nouvelle 26), habiendo ya sufrido el olvido de su amigo, no se convencerá de su indiferencia hasta habérsela oído declarar con todas sus letras. Igualmente, en la nouvelle 59 una mujer denuncia la infidelidad de su marido ante sus hijos y sirvientes. Al conducirlos ante la escena del adulterio,

[elle] leur demanda en basset qui c'estoit ou lit de la chambriere [et] qui la dormoit avec elle. Et ses enfans respondirent que c'estoit leur pere, et les varletz dirent que c'estoit leur maistre.

(nouvelle 59, líneas 81-84)

[ella] les preguntó en voz baja quién era aquél que se encontraba en la cama de la camarera [y] que dormía ahí con ella. Y sus hijos respondieron que era su padre, y los lacayos dijeron que era su amo.

Vemos, pues, que no le basta con hacerlos testigos de los hechos, sino que necesita, además, obligarlos a que los enuncien oralmente.

La presencia constante de diálogos en las tres obras ha sido muy comentada por los estudiosos. De hecho, el empleo del

${ }^{7}$ Como ejemplos, la nouvelle 8,64 y la 65 , y en la obra inglesa, el desenlace: del Cuento del mayordomo, provocado porque un personaje cuenta al interlocutor equivocado sus aventuras. 
discurso directo constituye uno de los aciertos de la narración, que se estructura alrededor de un intercambio de réplicas. ${ }^{8}$ Poco importa que el diálogo se efectúe en el secreto de la intimidad o ante todo el mundo, los tres autores se complacen en reproducirlo ante nuestros ojos.

El motivo de la confesión, por ejemplo, reaparecerá a menudo en las tres obras, sin duda a causa de su novedad como práctica religiosa, pero también por la infinidad de posibilidades narrativas que ofrecía al escritor. ${ }^{9}$

Sî se mencionan las presiones eróticas ${ }^{10}$ y económicas ${ }^{11}$ que los curas ejercían sobre sus fieles durante estas entrevistas, parece también que fuera importante sacar a la luz las falsedades e hipocresías de los pecadores ante sus confesores, en ese acto sagrado durante el cual, más que nunca habría que haber buscado la honestidad.

Así, Boccaccio abre el Decamerón con la confesión del peor hipócrita imaginable, quien incluso en el lecho de muerte logra engañar a su ingenuo confesor (I-1). La novela III-3, como veremos, retoma el mismo tema y la novela VII-5 presenta a un marido celoso disfrazado de confesor para sorprender los secretos de su mujer, quien por su parte no hará más que declarar mentiras en el confesionario (relato análogo a la nouvelle 78).

${ }^{8}$ Se ha dicho acerca de las Cent Nowelles nowelles que "no hay una sola now'elle de las cien de la obra que no esté organizada alrededor de un diálogo, de un intercambio de réplicas esencialmente en discurso directo" (Jeay 1988, 196; véase además Pierdominici 1993, sobre todo 393-394). Esto es válido en cierta medida para las otras dos obras: en el caso del Decamerón, véanse Kirkham 1987. Branca 1985. Todorov 1969 y en el de los Cuentos de Canterbury: véase Cooper 1983.

${ }^{9}$ Como lo sugiere Cazalé-Bérard quien recuerda que la confesión obligatoria se establece en $1215(1987.36)$.

10 Por ejemplo, nowelle 44, líneas 161-170. Sobre todo en el Decamerón, como veremos más adelante, la confesión podrá constituir el pretexto ideal para la seducción o la planeación de las citas amorosas de los amantes (III-8, IV-2, entre otras). Véase otro ejemplo de presiones eróticas de un cura, aunque fuera del confesionario, en VIII- $2 \$ 46$.

11 Véanse las presiones del fraile a un moribundo en el Cuento del alguacil. Chaucer se inclinará más por la denuncia de la codicia de los curas que de sus amores prohibidos. El fraile, el bulero y el alguacil son todos acusados de avaricia y extorsión. aunque Absalón. en el Cuento del molinero es un clérigo seductor de damas. 
En cuanto a los Cuentos de Canterbury, no es casualidad que la obra concluya con las reflexiones alrededor de la confesión en el marco de la penitencia perfecta que describe el cura en su sermón. ${ }^{12}$ El religioso subraya la importancia de la coincidencia entre palabras y actos para que la confesión sea válida. Como veremos, el acento sobre la veracidad de lo que se dice estará ligado al interés que reviste la transmisión oral en las nouvelles.

Pasando a una palabra más pública, podríamos señalar que de la importancia asignada a la palabra pronunciada se desprende el interés por los rumores. Habitualmente, entre más se jura que se guardará un secreto, más seguro es que éste será propagado (nouvelle 40 y 62). En las Cent Nouvelles nouvelles, por ejemplo, afloran por todos lados frases tales como "Estas noticias volaron rápidamente por toda la ciudad", 13 "Poco tiempo después, la muerte de este zapatero fue conocida y publicada"; 14 "El otro guardó tan bien el secreto de su historia que todos se enteraron". ${ }^{15}$ Los rumores adquieren una fuerza tal que pueden hasta resultar funestos, como en el caso de la mujer de Clays Utenhoven (nouvelle 69), quien muere por haber dado demasiado crédito a los rumores de la muerte de su marido: convencidos de su viudez, sus parientes la obli-

12 Aunque, como se ha dicho, la posición de este sermón al final de los Cuentos de Canterbury puede ser cuestionada, dado que la obra quedó incompleta y sólo existen hipótesis acerca del orden planeado por su autor (Vaughan 1999).

13 "Ces nouvelles furent tost volées par toute la ville" (nouvelle 64, líneas. 114-115).

14 "Pou de temps après, la mort tresdesirée de ce cordoannier fut sceue et publiée" (nouvelle 67, líneas 41-42).

15 "Et l'autre tint si secret son cas que chacun en fut adverty" (nouvelle 40 , líneas 131-133). Véase en el Decamerón: "tanto andò il romore di vicino in vicino, che egli pervenne infino a' parenti della donna" (VII-4, \$28) ["Tanto pasó el rumor de un vecino al otro, que finalmente llegó a los parientes de la dama"], y también III-8, §37; IV-10, §30; V-6, §10; VI-3, §7. Por su parte, al final del Cuento del molinero, Chaucer pone en escena a todos los vecinos, quienes propagarán la historia del diluvio, y cuyas opiniones arruinarán para siempre la reputación del carpintero (I (A) 3846-3849). Este pasaje será citado más adelante. 
gan a volver a casarse y cuando el primer esposo reaparece, ella se deja morir de la vergüenza de haberle sido infiel. ${ }^{16}$

2. La propagación de la palabra

\section{A) La reputación (La Casa de la Fama)}

Nos encontramos, pues, con que la opinión pública ocupa un lugar capital en el universo de la nouvelle, donde constituye, por otra parte, una versión degradada de la reputación y el renombre corteses. Los estudiantes del Cuento del mayordomo parecen más preocupados por el efecto de las noticias de su fracaso ante el molinero, que por el hecho mismo de haber sido sus víctimas:

Oure corn is stoln; men will us fooles calle [...] when this jape is tald another day

$$
\text { (I (A) } 4111,4207)^{17}
$$

Han robado nuestro grano, todos se burlarán de nosotros [...] cuando esta jugarreta [que hemos sufrido] sea narrada en el futuro.

Los personajes de las nouvelles actúan por miedo a los chismes y para controlar la buena o mala fama que amenaza con perseguirlos en cualquier momento. El autor francés satiriza el establecimiento de esta "fama" que puede reposar sobre los hechos más absurdos, como es el caso del ignorante médico de la nouvelle 79 , cuyas lavativas lo han tornado célebre y respetable ante el pueblo; o el de la chica cuyo "agraciado y virtuoso renombre" inicial termina por convertirse en una reputación

${ }^{16}$ En X-9 $\$ 62$ hay una situación parecida, aunque resuelta en un tono menos trágico, desencadenada, nuevamente, por las noticias falsas acerca de la muerte del marido.

${ }^{17}$ Véase, también en el Decamerón, VII-4, §12 y VII-5, §58. 
basada no sobre sus cualidades sino sobre el escándalo provocado por el "maldito mal de almorranas" que la aqueja.

La Casa de la Fama ${ }^{18}$ pone al descubierto la tiranía que esta noción podía ejercer en la época. En este notable texto, Chaucer detalla los arbitrarios procedimientos de que se sirve la diosa Fama para conceder o denegar la celebridad a los humanos, al mismo tiempo que describe el sitic donde tienen origen los rumores. ${ }^{19}$ En un principio, vemos que en su búsqueda de nuevas fuentes de inspiración, el narrador del poema visita la morada de la Fama: un palacio invadido por un "gran ruido":

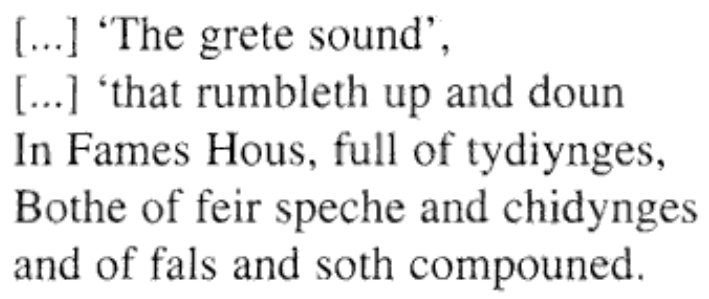

(1988b, vv. 1025-1029)

el gran ruido que ronroneba por arriba y abajo en la Casa de la Fama, lleno de nuevas compuestas tanto de admiración como de quejas, y de verdades entremezcladas con mentiras.

Parecería que Chaucer quisiera mostrar la dosis de falsedad que puede encontrarse en el fondo de las reputaciones más sólidas y de las noticias más verosímiles. La celebridad de un personaje no depende, pues, de sus méritos personales, sino de las azarosas decisiones de la Fama, diosa caprichosa cuyos designios son impenetrables.

Al lado del palacio de la Fama, se encuentra la enloquecedora "casa de los rumores": edificio en forma de laberinto construido por endebles palitos y que no deja de girar. Sus millares

18 Poema compuesto por Chaucer, anterior a los Cuentos de Canterbury (1988b).

${ }^{19}$ En el inglés de la época, como en latín y en español, fame podía significar "reputación" o "renombre", pero también "rumor". Chaucer juega con las dos significaciones (véanse las notas introductorias al poema en 1988b, 348 y 977). 
de puertas y ventanas no se cierran jamás; su techo está lleno de agujeros. Estos orificios, espejos de la boca y los oídos humanos, ${ }^{20}$ facilitan la circulación de las noticias, sean éstas verdaderas o falsas.

En este último escenario, la parte final del poema (de hecho inconcluso), presenta a una mentira y una verdad disputándose la salida de una ventana de la "casa de los rumores". Como no Hlegan a ponerse de acuerdo para decidir quien saldrá en primer lugar, deciden hacerlo al mismo tiempo, unidas, además, por un juramento de fraternidad eterna:

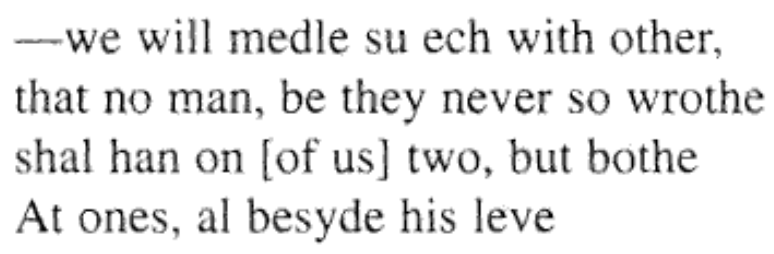

(1988b, vv. 2101-2105)

- Nos mezclaremos una con otra de tal manera [se proponen entre ellas] que nadie, ni el más furioso, podrá tener a la una sin la otra, sino siempre a ambas a un tiempo.

Y el narrador añade, decepcionado, "es así como vi a la falsedad y a la verdad amalgamarse en cada nueva que volaba".21

Estas reflexiones del autor inglés acerca de la autenticidad de lo que se dice o se oye acerca de los demás serán una constante en las tres obras, donde, además de reproducir el proceso de la transmisión oral, los escritores parecen denunciar las confusiones provocadas por la comunicación de informaciones falsas y el provecho que de esto se obtiene.

${ }^{20}$ Gellrich 1985, cap. V (aparte de este interesante análisis de The House of Fame, véase el de Cooper 1983).

21 "Thus saugh $\mathrm{I}$ als and soth compouned/ Togeder fle for oo tydynge" (1988b, vv. 2108-2109). 


\section{B) Los mensajes falsos}

En este contexto no es coincidencia que una de las nouvelles de la obra francesa que se estructura alrededor de la comunicación y eventual propagación de un mensaje, utilice precisamente un mensaje falso como objeto de atención. Se trata de la nouvelle 14, en la cual un eremita se las arregla para hacer creer a una viuda que su hija —a quien él quiere seducir-, dará a luz al próximo papa de Roma.

La presentación del tramposo se liga, en la misma frase, a la anticipación de su fracaso. Y es precisamente la "voz pública" la que funciona como señal de la caída del malhechor. El eremita, leemos en las primeras líneas de la narración,

soubz umbre du doulx manteau d'ypocrisie, faisoit des choses mervelleuses qui pas ne vindrent a cognoissance ne en la voix publicque du peuple jusques ad ce que Dieu plus ne vouloit son tresdamnable abus permettre

(nouvelle 14, líneas 12-15)

bajo la sombra del dulce manto de la hipocresía, hacía cosas increíbles que no llegaron al conocimiento ni a la voz pública del pueblo, sino hasta que Dios decidió no permitir más sus muy criticables abusos [el énfasis es mío].

El truco que el religioso emplea para que la viuda le confíe a su hija toma la forma de un falso mensaje divino: el seductor, aprovechando la oscuridad, imita la voz de un ángel que informa a la mujer que de la unión de la joven y el eremita nacerá el futuro papa y redentor de la Iglesia.

En esta primera fase, se trata ya de una transmisión, ya que el ángel no es más que el mensajero del "Creador quien me envía a anunciarte y ordenarte...".22 Y a su vez, las instruc-

22 "Je suis ung angel au Createur, qui devers toy m"envoye toy annuncer et commender..." (nouvelle 14, líneas 39-40). 
ciones que da implican la comunicación de un mensaje, esta vez dirigido al eremita mismo:

Tu t'en yras en la montaigne devers le saint hermite, et ta fille luy meneras, et bien au long luy compteras ce que a present Dieu par moy te commende.

(nouvelle 14, líneas 44-47)

Irás a la montaña con el eremita [le dice el ángel a la viuda] y a tu hija le llevarás; y le contarás con todo detalle esto que ahora Dios te ordena a través de mí.

Antes de que la orden sea cumplida, tendremos ocasión de ver que la mujer se acuerda del "dulce mensaje", y lo comunica a su hija:

Lors luy va dire tout au long l'angelicque nouvelle que en ceste nuyt Dieu luy manda...

(nouvelle 14, líneas 68-69)

Entonces va a decirle con detalle la angélica nueva que esa noche Dios le envió...

Se dirigen luego al anacoreta. Al verlo, la madre "lo jala aparte y le dice del principio al fin todo el hecho". ${ }^{23}$

La voz del ángel volverá a ejecutar su misión durante tres noches consecutivas, y nosotros veremos las tres ocasiones cómo la madre "cuenta a su hija las nuevas" (líneas 125-126) para de inmediato volver a buscar al eremita y transmitirle su mensaje:

Si la vieille hier luy fist ung grand prologue de sa vision, celuy de maintenant n'est de rien maindre

(nouvelle 14, líneas 132-134)

23 "le tire a part et luy va dire de bout en bout tout le fait..." (nouvelle 14, líneas $87-88$ ). 
Si la víspera la vieja le había hecho una gran historia de su visión, la de ahora no es en absoluto menor

dice el texto para la segunda vez, y en cuanto a la tercera:

la bonne mere $[\ldots]$ ne luy cela gueres sa nouvelle apparition (nouvelle 14, líneas 164-166)

la buena madre $[\ldots]$ no le ocultó en absoluto su nueva aparición.

Pero la propagación del mensaje no se detiene ahí. Una vez que la chica queda encinta, la madre "no puede aguantarse sin contárselo a su vecina más íntima". ${ }^{24} \mathrm{Y}$ dicha vecina, a sû vez, "no ocultó mucho tiempo a los otros vecinos y vecinas cómo, la hija de tal...", ${ }^{25}$ hasta que dicha "noticia se extendió con rapidez por las ciudades vecinas". ${ }^{26}$

Finalmente, cuando asistimos al nacimiento, no del futuro Santo Padre de la cristiandad, sino de una bebita,

La nouvelle de ce cas ne fut pas mains tost sceue que celle precedente;

(nouvelle 14, líneas 216-218)

La noticia de ese hecho no fue menos prontamente conocida de todos que la anterior.

Será, pues, la divulgación de esta última sorpresa lo que provoque la huida del eremita.

Nos hemos detenido con tal detalle en los pormenores de este relato para mostrar que aun cuando la transmisión de la

24 "ne se peut tenir que a sa plus privée voisine ne le comptast..." (nouvelle 14, líneas 202-203).

25 "Elle ne cela pas longuement aux aultres voisins et voisines comment la fille d'une telle..." (nouvelle 14, líneas 206-207).

26 "Ceste nouvelle fut tantost espandue par les ville voisines" (nouvelle 14, líneas 211-212). 
palabra funciona como motor de la acción, no se trata, de hecho, más que de la propagación de falsedades, lo que sin embargo no parece invalidar el proceso. La minucia de la descripción destinada a reproducir frases cuyo contenido es falaz parece probarlo. Entre mayor es el acento en el mensaje, más engañoso resulta éste, y el efecto cómico se refuerza.

Es solamente al ser por fin revelada la verdad cuando el relato termina, como si el interés del narrador residiera en la propagación de las mentiras, y una vez desenmascaradas éstas, no le quedará nada más que contar — salvo, tal vez, las nuevas intrigas que el religioso podría inventar para "engañar a otra mujer u otra niña, en otro país"27 (líneas 219-220)-, pero esa ya sería otra historia.

Cuando Chaucer aborda el mismo tema, encontramos de nuevo un falso mensaje de Dios. En el Cuento del molinero, para alejar al carpintero de su esposa Alison y ocupar su lugar durante la noche, el estudiante Nicolás finge haber recibido del cielo las señales del nuevo diluvio. El imaginario mensaje divino, desentrañado en un ambiente misterioso para engañar mejor al marido, es aquí el medio que usa Chaucer para parodiar a la vez el texto sagrado y el desciframiento y transmisión de los mensajes en general. Si bien Nicolás finge interpretar, para transmitirlas, las señales divinas sin problemas la primera vez, habrá un segundo mensaje, menos sublime pero mucho más âpremiante que no llegará a ser correctamente descodificado. En efecto, cuando Nicolás, sintiendo el trasero quemado pide desesperadamente, "iagua, agua!" para aliviar su dolor, el carpintero tomará sus gritos como la señal del diluvio. ${ }^{28}$

27 "en aultre païs [...] une aultre femme ou fille decevoir..." (nouvelle 14, línea 220).

${ }^{28}$ Su quemadura se debe a la venganza que Absalón, otro pretendiente de Alison, había preparado para ésta. La noche en que Alison se divertía con Nicolás, Absalón había venido a buscarla, y con el fin de deshacerse de él, Alison le prometió un beso, para el cual, aprovechando la obscuridad, le ofreció el trasero en vez de la boca. Absalón se va completamente humillado, pero planea pedirle a la bella otro beso, lo que le permitirá vengarse. $Y$ es en este momento cuando inter- 
Aun cuando a fin de cuentas este relato, como buen fabliau, parece hacer burla del marido, no sólo cornudo sino además tomado por un loco que espera diluvios a la primera provocación, Nicolás también saldrá bastante mal parado de la aventura, durante la cual sus intentos por comunicarse no siempre se revelarán eficaces.

Otro cuento de Canterbury, el del bulero, pone, a su vez, en duda la intencionalidad de quien produce los mensajes. El bulero, cuya ocupación es la predicación, es decir, la transmisión de la palabra divina, es a tal grado un pecador endurecido, que sus sermones resultan sospechosos. Pronunciada con una extraordinaria elocuencia y provista de toda clase de buenos consejos y ejemplos moralísimos, su prédica es, pues, rechazada por los peregrinos, quienes saben que ha sido producida no para la edificación de los fieles, sino para el propio provecho del orador (con el fin de extraer limosnas). Así, un mensaje puro y verdadero puede resultar más inaceptable que la peor mentira.

En el Decamerón existe un interés análogo hacia esta especie de perversión de la transmisión de los mensajes. La novela III-3 es, desde esta perspectiva, una versión sofisticada de los abusos de la comunicación: una dama casada se lamenta ante su confesor de las insinuaciones amorosas de un caballero, pidiéndole que hable con el culpable para que su virtud sea respetada. El confesor, indignado, transmitirá de inmediato el mensaje, convirtiéndose así, sin saberlo, en un eficaz alcahuete para la dama. De hecho, el caballero nunca había pensado en ella, y no es sino a raíz de los reproches del religioso como

viene Nicolás. Tratando de mejorar la broma de Alison, se pone en su lugar para el supuesto siguiente beso, dejando salir una flatulencia en plena cara de su rival. pero, para su sorpresa recibe la marca de una plancha ardiente en respuesta. La flatulencia como antilenguaje nos lleva a otra forma de perversión de la comunicación; Cooke la lee como una alusión al demonio, en tanto que contrapartida blasfema de la Trinidad, pues opondría las pestilencias demoníacas al sagrado aliento del Espíritu Santo (1978). El simbolismo de la flatulencia es examinado por Gaignebet 1986 y 1974. 
acepta el juego iniciado por la intrigante. Así pues la dama continuará sirviéndose del cura, sin que éste lo sospeche, para establecer la comunicación que les permitirá convenir en los detalles de la primera cita.

Partiendo siempre de una queja de la dama, el método resulta un éxito: la hipócrita cuenta al confesor hechos que en su versión sucedieron la víspera, cuando en el fondo los está proponiendo al amante para ser realizados al día siguiente. Como es muy probable que el religioso reprenderá al seductor revelándole todos los detalles del crimen que supuestamente ha cometido, la dama puede estar segura de que su amante se apresurará a cometerlo lo antes posible. ${ }^{29}$

Boccaccio invierte aquí uno de los esquemas habituales de las nouvelles, en el que una mentira del pasado se revela en toda su falsedad por el sólo hecho de haber sido transmitida y propagada. Aquí, al contrario, una desfiguración evidente a los hechos pretéritos adquiere estatus de posibilidad gracias al discurso, para convertirse posteriormente en un dato cabal de la realidad. Y todo ello, simplemente por obra de la palabra.

Como se ve, los tres autores comparten el interés por representar el proceso de la transmisión oral, a la vez que se complacen en inventariar los abusos a los que ésta se puede prestar.

\section{El cuestionamiento a la autentificación}

A) La ilusión de oralidad y la ilusión referencial ${ }^{30}$

Si la transmisión oral podría ser una de las obsesiones de las nouvelles, encontramos en ellas, además, una tendencia a

${ }^{29}$ El mismo esquema de la mentira que se convierte en realidad por el sólo hecho dé ser pronunciada se encuentra en el relato I-I del Decamerón. En éste, Ciappelleto termina convertido en santo milagroso, aun cuando su confesión, totalmente falsa, no había sido más que una burla (véase también II-7).

${ }^{30}$ Retomo aquí los términos de Jeay, quien anota que en las nouvelles "ilusión referencial e ilusión de oralidad son inseparables" $(1988,196)$. 
cerrar el relato con una última reproducción de esta transmisión. La escena final de la narración es, a menudo, aquella donde los personajes van a platicar su aventura a otro lado, a menos de que se contenten con reírse de ella entre los participantes. En las Cent nouvelles nouvelles, la 15 termina cuando los dos monjes

Après ceste adventure, s'en retournerent vers leur hostel, tous devisans de ceste advenue.

(nouvelle 15, líneas 103-104)

Después de esta aventura volvieron a su posada, platicando entre ellos de lo que pasó.

Veremos asimismo a un caballero presumir de sus logros amorosos contándolos alegremente "a los galanes y compañeros de suerte", 31 al igual que la víctima de una broma se apresura a buscar un público para sus desgracias, como el caballero que habiendo sido ridiculizado por la camarera que intentaba seducir,

au palais s'en va, ou il compta son adventure a pluseurs gens de bien que en risirent bien fort.

(nouvelle 17, líneas 143-145) $)^{32}$

al palacio se fue, donde relató su aventura a muchas gentes de bien que rieron mucho.

Del mismo modo veremos en el Decamerón cómo, después de sus aventuras, Andreuccio encontró "a sus compañeros y les contó lo que le había sucedido". 33

En el Cuento del alguacil de Chaucer la víctima de una afrenta la narra en la corte de su señor. Y, finalmente, en el Cuento

31 "aux galans et compagnons de sorte" (nouvelle 18, líneas 150-152).

32 Véase también nouvelle 7, 40, 42, 57, 62, 63, 64, 97 y 100 entre otras.

33 "li suoi compagni... trovò... A' quali ciò che avvenuto gli era racontato" (II. $5, \S 85)$. Véase también II-1, \$32. 
del molinero se evoca la transmisión oral sin reproducirla puntualmente: al final del relato, la historia del diluvio que engañó al carpintero causándole una accidentada caída, se extenderá por doquier:

That he was holde wood in al the toun;
For every clerk anonright heeld with oother [...]
And every wight gan laughen at this stryf

(I (A) 3846-3849)

En el pueblo lo tuvieron por loco, todos los estudiantes [o clérigos] estuvieron de acuerdo en ello [...] y todo el mundo se reía de la aventura.

Sin embargo, en los textos de Chaucer y de Boccaccio el fenómeno es menos notorio que en el francés. Se podría explicar esta divergencia a partir de las diferencias estructurales de las tres obras, con lo que resultaría que como el Decamerón y los Cuentos de Canterbury tienen un marco narrativo que les sirve de procedimiento para otorgar autenticidad a sus relatos, no necesitan reforzar esta estrategia al interior de ellos para que parezcan verídicos.

Ya hemos dicho que la importancia del marco narrativo reside, en parte, en el hecho de representar una situación de comunicación reconocible por todos los lectores. Esto les permite familiarizarse con el texto e incluso deslizarse al interior de la ficción, ocupando el lugar de los personajes auditores (Almansi 1975; Strohom 1983, 138). El marco narrativo constituye así un recurso eficaz para dar autenticidad a la ficción. Es exactamente ahí donde Chaucer y Boccaccio apelan a situaciones históricas (la peste, que los contemporáneos sufrieron, o una peregrinación, situación cotidiana de la época). En las Cent Nouvelles nouvelles los narradores llevan los nombres de personajes reconocidos de la corte de Borgoña, también con el objeto de situar la obra en un contexto histórico real. Sin em- 
bargo, a falta de un marco narrativo explícito, en este texto es necesario revisar de cerca la representación del proceso de la transmisión oral al interior de los relatos y constatar que éste constituye una de las más poderosas armas del autor para dar autenticidad a su obra. Si los personajes cuentan por todos lados sus aventuras, es más probable que el autor también las haya oído. ${ }^{34}$ Y no es casual que repita, al final de sus historias, frases que evocan el método oral de un coleccionista de anécdotas: "como me lo contaron", 35 "según lo que me dijeron" 36

Por otra parte, el recurso a los diálogos, como ya se dijo, es otro procedimiento fundamental para dar autenticidad al género, pues ofrece la apariencia de transcribir literalmente una situación oral: las estructuras sintácticas, los giros coloquiales de las frases así como las exclamaciones y juramentos, parecen constituir un registro fidedigno del estilo ordinario y familiar propio de la lengua hablada. ${ }^{37}$

Pero si dichos procedimientos podrían constituir rasgos centrales del género, justo por esta causa adquieren resonancias inquietantes, pues, irónicamente, cada autor emplea la palabra como recurso para dar autenticidad, a la vez que a lo largo de toda su obra, esta misma palabra se utiliza fundamentalmente para engañar y confundir a los otros, y casi nunca como mediadora de alguna verdad.

34 Es necesario precisar que Todorov señala un fenómeno parecido cuando habla del "testigo", ese personaje secundario a quien se narran las aventuras al final del relato, o que habrá sido testigo de ellas, y con quien el lector podrá identificarse (1969, 13-14). Interesa sobre todo el primer caso, pues se trata de una transmisión de las historias. Todorov da como ejemplo la III-10 y se podrían añadir la I-2 o la II- 1 , entre otras.

35 "comme l'on me compta" (nouvelle 22, líneas 123-124).

36 "a ce qu'on me dist" (nouvelle 25, línea 85). O bien, "... n'est encores venu a ma cognoissance" (nouvelle 23, línea 94) ["...no ha llegado aún a mi conocimiento"]. Véanse también nouvelle 17, línea 145; nouvelle 25, línea 86; nouvelle 43, líneas 95-96.

37 Vemos a un marido furioso gritándole a su mujer "Assez! Hault! Hen! Hen! dit il, et par saint Jehan! ce marché ne se passera pas sans..." (nouvelle 97, líneas 61-62) ["¡Basta!, ¡alto!, ¡eh!, ¡eh! - dijo él- iy por san Juan, este negocio no va a terminar sin..."]. También encontramos expresiones como "Prenez chula..." (nou- 
Así pues, si el autor justifica sus textos alegando que sólo narra historias verdaderas que le fueron relatadas a él mismo es porque la palabra pronunciada garantiza la veracidad de la narración. Sin embargo, el contenido de sus relatos no es más que un largo rosario de engaños orquestados por manipulaciones del lenguaje más o menos hábiles que nos llevan a pensar que los personajes rara vez emplean la palabra para comunicarse honestamente. Como se señaló, uno de los motivos que reaparece constantemente en las nouvelles es la separación entre las palabras pronunciadas y las intenciones o los pensamientos verdaderos. Sin ir más lejos, podemos partir del número de veces en que las frases "es verdad que", "en verdad" 0 "verdaderamente", 38 son empleadas para introducir más fácilmente una falsedad. El hecho mismo de proclamar que se dirá la verdad resulta casi siempre sospechoso.

De este modo, el recurso mismo que sirve para probar la autenticidad de las historias no hace más que corroborar su falsedad, a la vez que pone en cuestión el valor de la palabra como instrumento de comunicación.

velle 75, línea 121) ["Tómesste"], por "Prenez celui-la" ["Tómese éste"], donde se tunscribe la pronunciación tal como debio sonar, equivalente a un my mexicano ips'ontá?" por "¿pues dónde está?". Al respecto del ejemplo francés. Sweetser senala que se trata de una "forma del norte de Francia" (1996, 605).

Habría que mencionar también las constantes repeticiones de palabras en respuestas que retoman los mismos términos que las preguntas (nouvelle 84, lineas 27 28; 29-30), véase también Jeay $1988,196, n .14$, en cuanto a los relatos franceses; y Tos comentarios de Branca (1985. 358 y ss.) acerca de los giros populares y dialectales en el Decamerón (señala sobre todo II-5 \$53; III-I \$37; III-8 \$45; VIII$2 \$ 12,14$ y $43 ;$ VIII-6 \$17; VIII-9 \$15, 39 y 70; IX-5 \$34). En cuanto al texto de Chancer, véanse las precisiones que hace Caluwe.Dor, en la traducción al francés de los Cuentos de Camerbury (Les Contes de Canorberv), an su introducción al Cuento del mayordomo (1977).

38 Véase nouvelle 13, líneas 99.100, nowvelle 19, línea 57, nouvelle 3, líneas 26 y 41 , nouvelle 87, linea 75, y la nouvelle 89, linea 68: "verdadero como el Evangelio". En el Decamerón veremos a Cipolla introducir sus mentiras con vera cosa e" o "E il vero" (VI-10), par. 48 y 49), así como en al Cuento det molnero de Chaucer. Nicolás comienza su falsa historia del diluvio con "I wol nat lye" (I (A) 313) lno voy a mentir]: y May, en el Cueno tel comerciante. trtroduce sa discurso hipócrita con "I shall nat lyen" (IV (E) 2371) [no mentiré]. 


\section{Conclusión}

Todo lo anterior nos lleva a concluir que el interés predominante sobre la transmisión oral en las nouvelles no sólo se asocia paradójicamente a la cuestión de la veracidad de lo mismo que se transmite, sino que apunta a un serio cuestionamiento acerca del papel y el funcionamiento de la palabra.

La representación de la actividad oral en las nouvelles se debe ver pues, no simplemente como un rasgo de la literatura medieval donde la huella de la oralidad queda evidenciada en la puesta por escrito, sino como una estrategia que permite a los autores hacer verosímiles las historias narradas. Sin embargo, dicha estrategia, cuyo fin, en último caso, sería ocultar el trabajo literario de los textos, revela, como parte de su propio mecanismo, la ficcionalidad misma de lo narrado, pues la palabra termina por caracterizarse como portadora de contenidos ilusorios o engañosos que rara vez corresponden a la "verdad de lid historia".

El hecho de que la palabra pronunciada se presente no en su calidad de instrumento de comunicación sino como objeto de interrogación importa en la medida en que esa misma palabra que se pone en duda constituye la materia prima de la propia literatura. Si el "arte de narrar" tiene el alcance aquí señalado para el género de la nouvelle, proporcionándole incluso la estrategia para otorgarle autenticidad, resulta preocupante que sea justamente acerca de la palabra dicha como se nos sugiere la mayor cautela. Como si a través de este juego de paradojas los autores situaran su postura, tanto respecto de la propia actividad creativa como del lugar de la obra literaria, bajo el signo de la ambigüedad. Sugerirían así que esta literatura que se pretende simple registro de lo que "se dijo" y por ende de lo que "sucedió", no puede escapar a la condición esencial de toda obra de ficción.

$Y$ es tal vez a causa de esto que las nouvelles revelan, a través de la multiplicidad de máscaras de sus distintos narrado- 
res, la fatalidad del escritor, quien, a pesar de sus reivindicaciones de no reproducir más que la "verdad", termina inevitablemente por refundir esa "verdad" para transformarla en creación poética. Se constata así, como Howard Bloch ha precisado, que "la única verdad que la poesía no podrá afirmar jamás sin transgredir su propio estatus de ficción, es que ella misma es una ficción" (1990, 56).

\section{REFERENCIAS}

Almansi, Guido, 1975. The Writer as a Liar. Narrative Technique in the Decameron, Londres y Boston, Routledge \& Kegan Paul. Azuel a Bernal, Ma. Cristina, 2006. Del Decamerón a las Cent Nouvelles nouvelles. Relaciones y transgresiones en la nouvelle medieval, México, UNAM.

BLoch, Howard, 1990. "New Philology and Old French", Speculum 65-1, 38-58.

Boccaccio, Giovanni, 1985. Decameron, Vittore Branca (ed.), Milano, Mondadori Editore.

-, Decamerón, 2001. Tr. al español de María Hernández Esteban, Madrid, Cátedra (Col. Letras Universales).

- 1986. Boccaccio Medievale e Nuovi Studi sul Decameron, Firenze, G. C. Sansoni.

Cazalé-Bérard, Claude, 1987. "Jeux de masques. Fonctions narratives et thématiques dans le Decameron", Revue des études italiennes $14,32-59$.

CHAUCER, Geoffrey, 1988a. The Canterbury Tales, en The Riverside Chaucer, L. D. Benson (ed.) [basada en la ed. de Robinson], Oxford University Press, $3^{\text {a }}$ ed., pp. 3-328.

- 1977. Les Contes de Cantorbéry, (2 vols.), tr. al francés Juliette Caluwé-Dor, Gand, Éditions Scientifiques E. Story-Scientia.

- 1988b. The House of Fame, en The Riverside Chaucer, L. D. Benson (ed.) [basada en la ed. de Robinson], Oxford University Press, $3^{a}$ ed., pp. 347-373. 
Les Cent Nouvelles nouvelles, 1928. Ed. crítica de Pierre Champion, Paris, Droz, (3 vols.).

Les Cent Nouvelles nouvelles, 1991. Trad. al francés moderno de Pierre Dubuis, Lyon, Presses Universitaires de Lyon.

Les Cent Nouvelles nouvelles, 1996. Ed. crítica de Franklin P, Sweetser, Genève, Droz.

COOKE, Thomas (ed.), 1978. The Old French and Chaucerian Fabliaux, Columbia \& London, University of Missouri Press.

COOPER, Helen, 1983. The Structure of the Canterbury Tales, London, Duckworth.

Dubuis, Roger, 1973. Les Cent Nouvelles nouvelles et la tradition de la nouvelle en France au Moyen Âge, Grenoble, Presses Universitaires de Grenoble.

Galgnebet, Claude, 1986. A plus Hault Sens. L'Esotérisme Spirituel et Charnel de Rabelais, Paris, Maisonneuve et Larose, ( 2 vols.).

-, 1974. Le Carnaval, Paris, Payot.

Gellrich, Jesse M., 1985. The Idea of the Book in the Middle Ages:

Language Theory, Mythology and Fiction, Ithaca and London, Cornell University Press.

JEAY, Madeleine, 1988. "L'enchâssement narratif: un jeu de masques. L'exemple des Cent Nouvelles nouvelles", en Masques et déguisements dans la littérature médiéval, Marie-Louise Ollier (ed.), Montréal, Presses de l'Université de Montréal, pp. 193-201.

KIrkham, Victoria, 1987. "The Word, the Flesh, and the Decameron", Romance Philology 41-2, 127-149.

Perouse, Gabriel A., 1977. Nouvelles françaises du XVIe siècle. Images de la vie du temps, Genève, Droz.

Pierdominici, Luca, 1993. "Le Style direct dans les Cent Nouvelles nouvelles", Lingua e Stile 28-3 (septiembre), 377-399.

RASMUSSEN, Jens, 1958. La prose narrative française du XVe siècle, Copenhaguen, Ejnar Munksgaard.

Stronom, Paul, 1983. "Chaucer's Audience (s): Fictional, Implied, Intended, Actual", The Chaucer Review 18-2, 137-145.

Todorov, Tzvetan, 1969. Grammaire du Décaméron, Paris, The Hague, Mouton. 
VaUGHAN, Míceál F., 1999. "Creating Confortable Boundars: Scribes, Editors, and the Invention of the Parson's Tale", en Rewriting Chaucer. Culture, Authority and the Idea of the Authentic Text (1400-1602), Thomas A. Prendergast y Barbara Kline (eds.), Ohio, Ohio State University Press, pp. 45-90.

ZumThor, Paul, 1972. Essai de poétique médiévale, Paris, Seuil. 